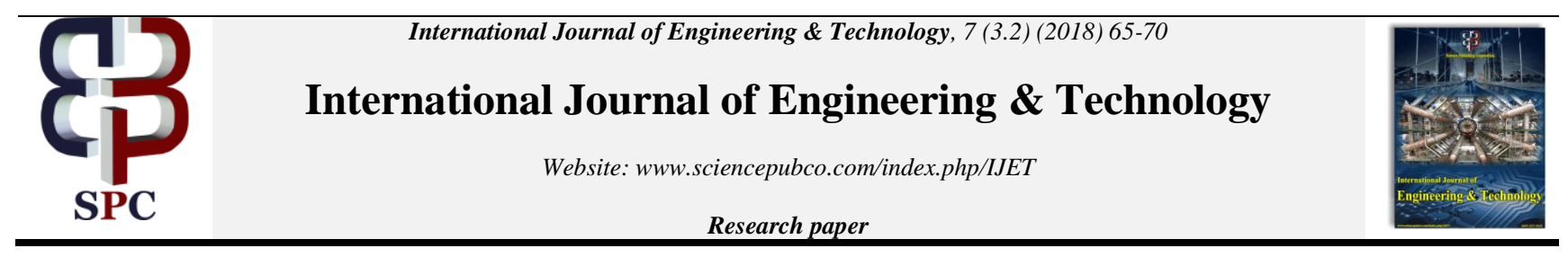

\title{
Effective Cluster Model of Thermal Power Company Management
}

\author{
Vira Chevhanova ${ }^{1}$, Kseniia Chichulina ${ }^{2}$, Vitaliya Skryl $^{3}$

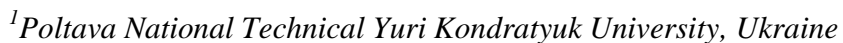 \\ ${ }^{2}$ Poltava National Technical Yuri Kondratyuk University, Ukraine \\ ${ }^{3}$ Poltava National Technical Yuri Kondratyuk University, Ukraine \\ *Corresponding Author E-Mail: Chevganovavera@Gmail.Com
}

\begin{abstract}
The aim of this study is to determine the need for cluster formations; to identify the influence factors on the creation of a cluster of thermal power companies in Poltava region. The method of evaluating the efficiency of formation of this cluster has been developed.

The methodological framework of this research is general scientific dialectical method of cognition, in which the research object is studied as a dynamic system in the process of its development. The formation of the main directions of thermal power company development was carried out on the basis of dialectical, historical and systematic methods. In the process of studying and generalization of scientific and practical development methods of comparison, analysis and synthesis, induction and deduction were applied. Also the study is based on regulatory and economic instruments, economical studies and studies of scientific research institutions.

As a result of the study the main participants of the cluster formation were identified. So it may be comprised of the members of the cluster, generating thermal energy, the thermal energy consumers and the region where the cluster of thermal power companies will be formed. According to the participants of cluster associations the factors of influence on economic and social effect from implementation of the cluster thermal power companies in the Poltava region were formed. We determined that to reduce the rate for thermal energy it is necessary to conduct a number of activities. The application of the proposed measures will significantly reduce the services cost of thermal power companies. The cost of thermal energy and the distribution among the participants of cluster associations were calculated on the example of Poltava region utility production enterprise of heat economy "Poltavateploenergo". The participants are heat producers, transport companies, distribution and heat supply companies, repair work companies, construction work enterprises. It is established that the overall effect of cluster members has both quantitative and qualitative nature. The impact on consumers is qualitative. It is based on the fact that the tariff for consumers remained unchanged in the medium term (five years). The essence of economic effect is in the quality and timeliness of services thermal management. The overall effect of its work influences all members. It occurs when there is the formation and implementation of cluster thermal power companies.

But in addition to the advantages of cluster associations its major problems were presented in the work. Among them there are the following problems: the lack of informativeness of executive authorities and business representatives in the application of the cluster approach; the lack of public policy to ensure the systematic approach and organization of interaction between different levels of executive authorities in the implementation of cluster projects; lack of institutional and financial support to cluster initiatives; lack of trained personnel in the organizational aspects of cluster technologies; the lack of effective methodological base for the application of cluster technologies. Scientific novelty of received results is the development and calculation of economic effect from the formation of a cluster of thermal power companies both at the regional level and at the level of the enterprise and the consumer.
\end{abstract}

Keywords: cluster, competitiveness, efficiency, heat and power company, region.

\section{Introduction}

Nowadays heat power companies of Ukraine's regions are in a difficult economic situation and face the losses. This is due to the lack of competitiveness of this type of service. So the approach based on regional development is becoming increasingly relevant. The main role in this approach belongs to clusters and cluster policy. The cluster approach will improve the efficiency of thermal power companies by bringing industry, government, and local institutions for constructive dialogue to improve results and offers effective mechanisms of co-operation between business and governments. It will contribute to the most effective innovative activi- ty in the sphere of thermal economy and raising competitiveness of the region.

\section{Main Body}

The cluster, as a territorial socio-economic entity, has a long history and is researched in many studies. General characteristics and mathematical justification of clusters and clustering are reflected in the studies [1 - 17].

In particular, in [1], the authors note that the process of transformation can be accelerated through the creation of bioeconomy clusters, which includes industry, academia and investors. Active management of such a coordinated cluster helps to identify early 
technology and market trends and to realize the regional potential for biotechnology more quickly. It is investment in the management cluster has that effect. The formation of such a cluster reduces the time to market as a critical competitive advantage.

In $[2,3]$ it is identified that clustering is an important method of unsupervised learning with extensive use of data, data mining, pattern recognition and intelligent information processing. However, the existing clustering algorithms generally include one or more user-specified parameters as input. The clustering results strongly depend on these parameters. In order to solve this problem the independent clustering algorithm parameters based on the dominating sets and the algorithm for cluster enterprises were proposed.

It should be noted that clusters are faced with a situation in which collective identity creates cohesion and effectiveness of the joint cooperation. It is difficult to select the cluster member; you need time to adapt to changes and to prevent unpredictable situations [4].

Also, some authors [5] propose to use the index of the cluster reliability used to select the clustering algorithm of the enterprise. It works by assessing the quality of the members of the cluster formation, the formation of the major candidates in the cluster, and evaluate their skills. Most of the existing indices of actions to do is an assumption, so the authors propose using a new measure of the reliability of the cluster.

In [6], the authors observed that in the era of "big data" large amounts of data across multiple distributed objects can be combined into a centralized location for further analysis, which refutes the assumption of traditional methods of clustering based on the centralized model. To solve this problem, we propose an efficient clustering scheme using the boundary information (DCUBI), which has flexibility and scalability.

Regarding the cluster analysis, it is often seen as a certain momen of time, ignoring previous analysis of the cluster product. In [7] the scientist proposes a model called the evolution of cluster analysis that considers three phenomena that may appear in the future: (1) changes in the number of clusters; (2) changes in the characteristics of the clusters; (3) cross-cluster migration of objects.

The role of creating industrial clusters in the literature [8] formed the modern thinking that for small businesses the only way to become competitive in the world markets is possible due to the increase of agglomeration and collective action.

The formation of clusters for regional development is considered in [9]. The authors reveal the usefulness of finite mixture models (FMMM) for regional analysis. FMMM combine clustering methods and model switching, providing powerful tools for coproduction of the dating of the business cycle and clusters of regions. They share similar characteristics of the business cycle. The example of the European regional data shows good performance of the proposed method.

The creation of cluster associations at the level of small producers and family farms are considered in [10]. The goal of the research of these authors is to create profiles for small families, which are in the region and to identify relevant characteristics of these profiles.

Regarding the mathematical study of clusters it should be noted that the authors also have different approaches to this issue.

The study [11] presents the model of dynamic clustering by the method of equivalent simulation for a two-stage cluster photovoltaic (PV) plant, which is the key instrument for analysis of dynamic response of a distribution network with high penetration movement.

A comprehensive study of clustering: the output of the methods and development made at different times are presented in [12]. These authors also define a cluster as "unsupervised learning", where objects are grouped according to the similarities among them. There are various methods for clustering of objects, such as hierarchical, distributed, based on the density and the model. The approaches used in these methods are discussed concerning their application and compliance. Also similarity measure and evalua- tion criteria, which are the main component of clustering, are presented.

An overview of some existing energy projects discrete modeling, the discussion of energy issues related to the management of input data are presented in [13]. The authors propose an operation-based concept for modelling energy consumption in production system and put the focus on how load profiles can be obtained, processed and entered into the simulation model depending on its variability and complexity associated with power equipment. The basic aim of this article is to present possibilities for modeling complex behavior, energy consumption of various pieces of equipment using stochastic distributions.

Some authors propose new methods for clustering and recognition of multidimensional time series based on multivariate statistical analysis [14]. The algorithm consists of four steps, which get the essential features of multidimensional time series of home users with an emphasis on seasonal and temporal profiles, among others. The methodology was successfully implemented and tested in the framework of energy efficiency program. The electric company Alagoas (Brazil) is presented as an example. The results were compared with the known method for clustering time series. The new method is able to detect a greater variety of models. The author identifies opportunities of the proposed method to take account of consumption regarding the simultaneous influence of other variables, except for the curves of the load. This is an important aspect in the decision-making process in the field of energy distribution.

In [15] the researcher presents an evaluation of the potential for renewable energy in Romania by clustering based on method of data mining. Available data on installed capacity, voltage level, type of renewable technology and geographical location of potential renewable energy sources for electricity production was scheduled for representative areas using K-means clustering algorithm. The potential was estimated on the voltage levels and technologies of renewable energy sources (wind, solar, hydropower, biogas, biomass, cogeneration). The resulting zones can be a useful working tool for the modernization of substations, upgrading transmission lines and distribution, as well as reviewing them for various parameters taking overload into account. This information may include the establishment of specific programmers to improve the planning and development of electricity networks in Romania. But the issue of economic effectiveness of cluster formations has not been fully taken into account in the studies of these authors on the organization of clusters activity There are not enough factors that influence the creation of clusters thermal management. Therefore, these issues are relevant today and require further study.

The aim of this study is the creation of cluster formations and identification of factors influencing the creation of the cluster thermal management; development of a method for assessing the effectiveness of forming a cluster association.

To achieve these aims in the study it is necessary to solve the following tasks:

- to identify the main participants of the cluster formation;

- to form a model of the cluster enterprises;

- to evaluate the efficiency of the cluster of heat and power company;

- to determine the overall economic effect from the creation of a cluster of thermal power company.

Today, the creation of cluster formations is one of the main objectives of the development strategy of Ukraine and its regions. The cluster should become a new regional production form of network organization among enterprises. The cluster will have the opportunity of innovation to adapt quickly to internal structures and respond to external environment. Therefore, there is every reason to implement the cluster approach as a strategic approach in solving problems of thermal management. The proposals are based primarily on the economic advantages of the cluster approach.

First, the cluster can unite the enterprises and organizations of various subjects of social and economic activities (research centers, agencies of state and local government, public organizations, industrial companies). It gives the opportunity to use the advantages 
of the two methods of coordination of economic systems: hierarchies inside the enterprise and the market mechanism. It will facilitate more effective and rapid use of new scientific discoveries, know-how, inventions, accelerated exchange of information.

Secondly, through the creation of linkages among cluster members results in economy of financial, material and human resources, there is a possibility of optimal use of investment.

Thirdly, the clustering of enterprises contributes to a more effective production process, stimulates the overall level of professionalism of the staff, contributes to the increase of enterprises and new jobs, moves the emphasis to the problems of heat supply from the centralized economy to the regional or local one.

In addition, clusters create favorable conditions to attract new entities of the cluster enterprises and trends that stimulate the development of existing businesses.

All this gives grounds to determine the peculiarities of cluster approach application and involves the formation of clusters in certain areas of the companies that perform different functions, but combined by one technological process, resulting in a final product created by the joint efforts of all the participants [16].

Clustering of thermal power companies does not create new entities, but the union on a mutually beneficial basis of already existing companies of manufacturers, suppliers of thermal energy. They form the strategy of innovative development of thermal power companies in a particular region.

But, the question of determining the economic efficiency of the cluster enterprises remains. After all, to assess future benefits is extremely difficult, especially in the context of the lack of the normative side of this question.

And also scientific studies attest to the powerful economic effect of the introduction of the cluster due to the significant reduction in transaction costs of enterprises [17].

To determine the effectiveness of the cluster creation, heat and power companies need to identify the main indicators for integrated assessment of the effectiveness of the cluster structure. These indicators can be divided into quantitative and qualitative, specific and general ones. But to develop a single cluster for all enterprises of the thermal economy of Ukraine is impossible, because every single company has certain specificity in its activities. This specificity is dependent on regional origin, scale, energy and others. Therefore, the analysis and calculations are made on the example of the heat power company of Poltava region.

Quantitative indicators are those that characterize the increase in economic effect from the creation of the cluster.

Qualitative indicators are indicators of the increase of the useful effect of cluster members cooperation in acceleration of social problems at the enterprise level and at the regional and state level. The specific indicators are associated with the regional location, industry specifics and an opportunity for the organizational structure of the cluster. For each cluster it is important to account for existing differences between the members of the cluster and linkages in production.

Common indicators of an estimation of efficiency of cluster structures require justification of all evaluation criteria. On their basis the total potential from implementation of the cluster is determined. Thus, the size of the economic effect of the cluster of thermal power company is a relative indicator. It shows the difference between the results and costs associated with the use of the means of production and labor.

It is possible to estimate the efficiency of thermal power companies in the cluster that reflects the efficiency of the process of formation of new organizational entities. Structural elements of the cluster and the efficient use of resources for their work are analyzed. Consequently, the overall effect of the introduction of a cluster of thermal power companies taking into account the interests of cluster members (service providers) and consumers of heat energy is calculated according to the formula:

$E f^{\text {over. }}=E f^{\text {over.memb. }}+E f^{\text {cons. }}+E f^{\text {reg }}$ where $E f^{\text {over. }}$ is the overall effect of the cluster of thermal power companies; $E f^{\text {overmemb. }}$ is effect of the work of cluster members; $E f^{\text {cons. }}$ is effect that consumers get from the introduction of the cluster model of thermal power companies; $E f^{r e g}$. - effect, which gets the region from the implementation of the cluster thermal power companies in Poltava region.

Thus, the economic effect from the thermal power companies cluster introduction on a manufacturer of thermal energy consumers and the region depends on a number of factors, which are shown in Fig.1.

I Factors affecting the size of the economic and social impact of the I creation of a thermal power companies cluster in the Poltava region

\section{1}

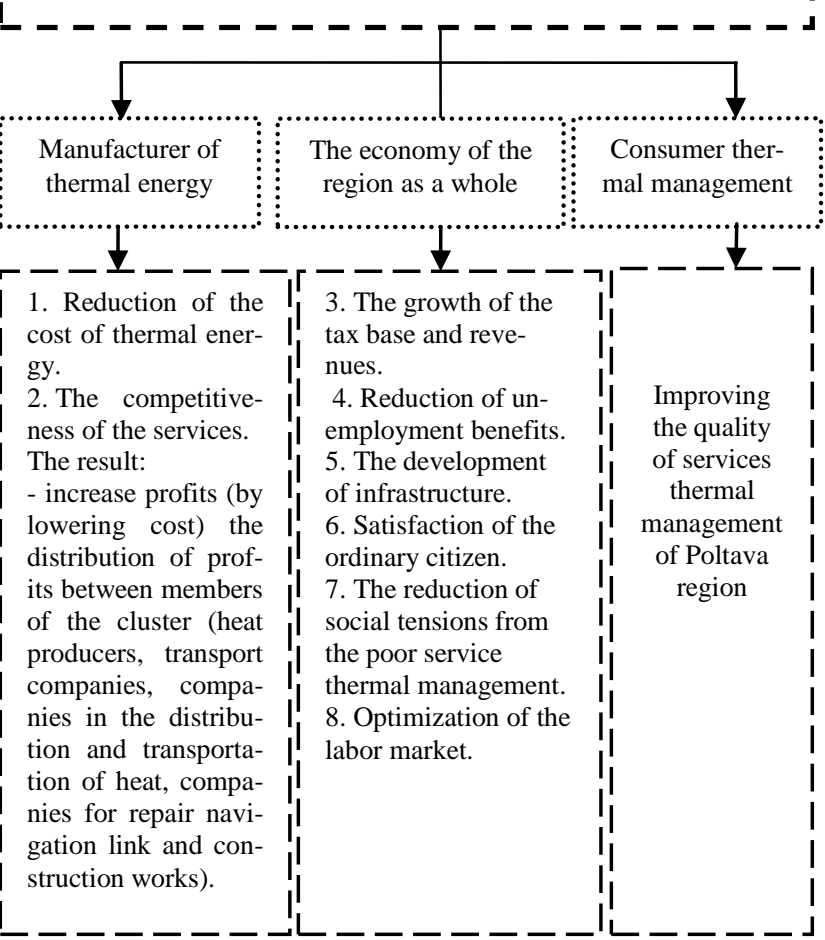

Fig. 1: Factors affecting the size of the economic and social impact

of the creation of a thermal power companies cluster in Poltava region

To reduce the rate/price for thermal energy it is necessary to conduct a number of activities depicted in Fig.2.

Consequently, the use of the proposed activities will provide an opportunity to significantly reduce the cost of services thermal management. 


\section{THE FORMATION OF TARIFFS FOR THERMAL ENERGY}

\begin{tabular}{|c|l|}
\hline D & 1. Annual plans for produc- \\
A & tion, transportation and \\
T & supply of thermal energy. \\
A & 2. State standards (norms) \\
& of consumption of re- \\
B & sources. \\
A & 3. Technical and economic \\
S & calculations and estimates. \\
E & 4. The rates of taxes and \\
& duties (mandatory pay- \\
& ments) \\
& 5. Prices in the planned \\
& period. \\
\end{tabular}

- Increase in volumes of production, transportation and supply of thermal energy in the economic development of settlement;

- Implementation of measures reducing the Plevel of costs for technological needs and losses of thermal energy;

- Implementation of regional programs of provision of metering of production and consumption of thermal energy;

- increasing demands for

F saving of fuel and energy

A resources.

C

$\begin{array}{ll}\mathrm{T} & \\ \mathrm{O} & \text { - increasing the technolog- }\end{array}$

$\mathrm{R}$ ical level of processes of

$\mathrm{S}$ production, transportation and supply of thermal energy;

- Implementation of measures aimed at the automation and mechanization of production;

- Application of advanced energy saving technologies.

- improving the organization of production and the improvement of working $\sum$ conditions;

- improvement of operational production planning, management systems, logistics business activities.

Fig. 2: Procedure of formation of tariffs for heat energy and suggestions for improvement

The effect size from the manufacturer thermal services can be calculated by formula 2 .

\section{PROPOSALS FOR THE IMPROVE- MENT OF TARIFF}

\section{RECOMMENDED \\ CHANGES:}

- Development and introduction of new technologies and equipment, aimed at technical re-equipment of the enterprises of housing and communal services;

- Reduction of specific consumption of energy and material resources;

- Establishment of production of new models of municipal vehicles and equipment for the needs of housing and communal services;

- Changes in the construction norms and rules for more active use of scientific and technological achievements;

- Update of fixed assets of enterprises of housing and communal services;

- Development and ensuring the implementation of incentive programs for efficient use of thermal energy consumers.

ORGANIZATIONALTECHNICAL MEASURES FOR COST REDUCTION

- increasing the technical level of production;

- change of volume and structure of production.

$$
E f^{\text {over.memb. }}=\sum_{i=1}^{n} E f_{i}-\sum_{i=1}^{n} K_{i}-\sum_{i=1}^{n} K_{o p .},
$$

where $\sum_{i=1}^{n} E f_{i}$ is the sum of the work effects of the cluster thermal management members (the effect is distributed among members of the cluster); $\sum_{i=1}^{n} K_{i}$ is the amount of capital expenses of the cluster members; $\sum_{i=1}^{n} K_{o p}$. is the amount of operating expenses from the operation of the cluster structure.

$$
\begin{aligned}
& E f^{\text {over.memb. }}=k^{1}\left(a_{1} \times C^{1}+a_{2} \times C^{2}+a_{3} \times C^{3}+a_{4} \times C^{4}+\right. \\
& \left.a_{5} \times C^{5}\right) k^{2}\left(A_{2}+A_{3}+A_{4}+A_{5}\right) \quad k^{3}\left(E_{2}+E_{3}+E_{4}+E_{5}\right)
\end{aligned}
$$

where $k^{1}, k^{2}, k^{3}$ is the odds ratio (within $0,3-0,7$ );

$a_{1} \ldots a_{5}$ is the percentage of cost reduction through appropriate intervention; $C^{1} \ldots . C^{5}$ is the cost of services of thermal energy producers of cluster structures; $A_{2} \ldots . A_{5}$ is capital investment to create the cluster thermal management (subject to its profitability $\left.q_{2} \times P r^{2} \ldots+q_{n} \times P r^{n}\right) ; E_{2}-E_{5}$ are operating expenses of the members of the cluster thermal management ( $b_{2} \times C_{2}^{\text {other }} \ldots+b_{n} \times C_{n}^{\text {other }}$ ).

Let's calculate the implementation of the thermal power companies cluster association of Poltava region, taking Poltava region utility production enterprise of heat economy "Poltavateploenergo" as an example of calculation of the overall economic impact according to statistics.

According to "Poltavateploenergo" as of 01.01.2017, the company released 854,0 thousand Gcal of thermal energy for centralized heating and centralized hot water supply [19]. In particular, for the needs of housing about $81 \%$ of the produced heat energy were sold, for budget establishments and organizations $-15 \%$, the rest - to other categories of consumers (except population). Therefore, for calculations, the cost of $1 \mathrm{Gcal}$ which is $1350,66 \mathrm{UAH}$ (as of 31.12.2017 [18]) for the largest group of consumers (i.e. the population) was selected.

When the cluster association of heat economy is created, production volume is distributed among stakeholders as follows: manufacturers of thermal energy - 65\%; transport company - 10\%; group of companies distribution and supply of heat $-10 \%$; companies manufacturing, repair and adjustment of work $-10 \%$; the firms providing buildings-flax and installation works $-5 \%$. Let's calculate the cost of thermal energy and distribution of production volumes between the participants in the process (table.1). According to the financial statements of the "Poltavateploenergo" as of 01.01. 2016 providing the payment of at least the entire debt of the population, the income of the enterprise would amount to 147600 thousand UAH.; other operating expenses according to the tariff structure are $6.5 \%$ [19].

On the basis of calculations and projections let's determine the size of the economic effect of the cluster association participants. The study is conducted on the example of Poltava region utility production enterprise of heat economy "Poltavateploenergo".

$$
\begin{aligned}
& E f^{\text {over.memb. }}=0,6 \times(0,2 \times 877,929+0,1 \times 135,06+ \\
& 0,1 \times 135,06+0,1 \times 135,06+0,05 \times 67,533) \\
& 0,3 \times\left(0,05 \times 147,62+0,05 \times 147,6+0,05 \times 147,6+{ }_{(4}\right. \\
& 0,05 \times 73,86)-0,3 \times(0,1 \times 87,79+0,1 \times 87,79+ \\
& 0,1 \times 87,79+0,05 \times 87,79)=114,72 \text { millionUAH. }
\end{aligned}
$$


Table 1: The calculation of the thermal energy cost and the distribution among the cluster association participants

(on the example of Poltava region utility production enterprise of heat economy "Poltavateploenergo")

\begin{tabular}{|l|c|c|}
\hline \multicolumn{1}{|c|}{$\begin{array}{c}\text { Participant of heat } \\
\text { economy process }\end{array}$} & $\begin{array}{c}\text { Percentage of its } \\
\text { participation in the } \\
\text { production of heat } \\
\text { economy process }\end{array}$ & $\begin{array}{c}\text { The cost of } \\
\text { services, } \\
\text { thousands } \\
\text { UAH. }\end{array}$ \\
\hline $\begin{array}{l}\text { manufacturers of thermal } \\
\text { energy }\end{array}$ & 65 & 877929 \\
\hline transporting companies & 10 & 135066 \\
\hline $\begin{array}{l}\text { group of companies } \\
\text { distribution and supply of } \\
\text { heat }\end{array}$ & 10 & 135066 \\
\hline $\begin{array}{l}\text { companies manufacturing, } \\
\text { repair and adjustment } \\
\text { work }\end{array}$ & 10 & 67533 \\
\hline $\begin{array}{l}\text { of the company for the } \\
\text { execution of construction } \\
\text { works }\end{array}$ & 5 & 1350660 \\
\hline Total & 100 & \\
\hline
\end{tabular}

Note:

1. The overall effect of cluster members has a quantitative and a qualitative nature. The impact on consumers is qualitative. It is based on the following assumption: the tariff for consumers remained unchanged in the medium term (five years).

2. The essence of economic effect is in the quality and timeliness of services thermal management.

The overall economic effect from the creation of a cluster of thermal power companies is shown in Fig. 3 .

The overall effect of the cluster operation of the thermal power companies in Poltava region

\begin{tabular}{|c|c|c|}
\hline $\begin{array}{l}\text { 1. Reducing the } \\
\text { cost of services } \\
\text { of thermal pow- } \\
\text { er companies. } \\
2 \text {. Introduction } \\
\text { of the innovative } \\
\text { component in } \\
\text { the tariff. } \\
\text { 3. Increase in } \\
\text { profit of thermal } \\
\text { power compa- } \\
\text { nies in the clus- } \\
\text { ter. } \\
4 . \text { Creation of a } \\
\text { competitive } \\
\text { environment. } \\
\text { Effect of the } \\
\text { service provider } \\
\text { of thermal pow- } \\
\text { er companies = } \\
114,72\end{array}$ & $\begin{array}{l}\text { 1. Growth of GRP. } \\
2 \text {. Growth of in- } \\
\text { vestment activity. } \\
\text { 3. Increasing em- } \\
\text { ployment in the } \\
\text { region. } \\
4 \text {. Increase in the } \\
\text { share of innovative } \\
\text { products in the GRP. } \\
5 \text {. Development of } \\
\text { small businesses. }\end{array}$ & $\begin{array}{l}\text { 1. Improving } \\
\text { the quality of } \\
\text { services of } \\
\text { thermal power } \\
\text { companies. } \\
2 . \text { Immutability } \\
\text { of the size of } \\
\text { the price/tariff } \\
\text { for thermal } \\
\text { power compa- } \\
\text { nies in Poltava } \\
\text { region for } 5 \\
\text { years. }\end{array}$ \\
\hline
\end{tabular}

Fig. 3: The overall effect of establishment and cluster operation of the heat power companies of the Poltava region

Despite the fact that clustering techniques have several advantages and prospects, there are challenges that impede their widespread and effective use. The main problems include: lack of informativeness of the representatives of executive authorities and business in the application of the cluster approach; the lack of public policy to ensure a systematic approach and organization of interaction between different levels of executive authorities in the implementation of cluster projects (a consequence of the lack of institutional and financial support of cluster initiatives); lack of personnel trained in the organizational aspects of cluster technologies; lack of effective methodological base for the application of cluster technologies [20].

\section{Conclusion}

Thus, considering the difficult situation in Ukraine and its regions with the payment for services of heating, there is an urgent need to change the situation. Therefore, the proposed approach regarding the development of new territorial and production clusters thermal power companies in the region might be one of the main methods of activation of innovation policy in the thermal sector in conditions of market relations.

But, for the implementation of such clusters on the territory of the Poltava region and other regions of Ukraine it is necessary to create certain conditions.

First, it is necessary to conduct a comprehensive analysis of the socio-economic development of the region and the leading sectors of the national economy of Ukraine. This will allow to identify the feasibility of creating cluster structures and to develop appropriate programs of clustering.

Second, it is necessary to develop state-level legislative framework for the support of innovative industrial clusters, which will determine the conditions of the clustering process, the actions of its members, and the process of taxation, which will attract foreign investors.

Third, it is necessary to adopt existing legislative documents, which will provide explanations of the content, role and place of clusters in the economic system of Ukraine and their financial provision

Fourth, scientific schools, the public and business representatives should be involved in the process.

The new territorial-production system of heat economy in the form of a cluster of thermal power companies of the Poltava region, which will produce competitive products (combined production of thermal and electric energy) has been proposed. Such formation will increase the performance of the enterprise of heat economy, will boost innovation processes in the enterprise country and at the level of region. It will involve the government, business and leading scientists into collaboration and resolution of the pressing problems of our society.

The size of the economic effect of the cluster formation testifies to the reality and possibility of realization of large investment projects. They will make it possible for heat and power companies of Ukraine's regions to become powerful and independent in the future, and for the citizens of our country to pay for the received heat services.

The authors propose the implementation of the cluster concept of the heat power companies of the city of Poltava. This concept will allow attracting extra resources by means of joint participants. The mechanism of implementation of clustering of the Poltava region utility production enterprise of heat economy "Poltavateploenergo" should be based on the principles of obligatory focus on achieving a positive economic result, the sustainable development of production, strengthening of cooperation and coordination of intersectoral and interregional type.

The creation of cluster structure on the basis of "Poltavateploenergo" will ensure production of competitive products; will enhance the activities of the heat power companies of innovation processes and effective mechanisms for coordination of government, business and education both at the level of individual companies, cluster member, and at the level of region and country.

\section{References}

[1] Kirchera M., Brevesb R., Tadenc A., Herzbergd D., «How to capture the bioeconomy's industrial and regional potential through professional cluster management», New Biotechnology, Vol.40, Part.A, (2018), pp.119-128.

[2] Cornuéjolsa A., Wemmertb C., Gançarskib P., Bennanic Y., «Collaborative clustering: Why, when, what and how», Information Fusion, Vol.39, (2018), pp.81-95, https://doi.org/10.1016/j.inffus.2017.04.008. 
[3] Houa J., Liub W., «Parameter independent clustering based on dominant sets and cluster merging», Information Sciences, Vol.405, (2017), pp.1-17, https://doi.org/10.1016/j.ins.2017.04.006.

[4] Pinkse J., Vernayb A., D’Ippolitoc B., «An organisational perspective on the cluster paradox: Exploring how members of a cluster manage the tension between continuity and renewal», Research Policy, Vol.47, Issue 3 (2018), pp.674-685, https://doi.org/10.1016/j.respol.2018.02.002.

[5] Rodrígueza J., Medina-Péreza M. Angel, Gutierrez-Rodríguezb A.Eduardo, Monroya R., Terashima-Marínb H. «Cluster validation using an ensemble of supervised classifiers», Knowledge-Based Systems, Vol.145, (2018), pp.134-144 https://doi.org/10.1016/j.knosys.2018.01.010

[6] Qiuhui T., Xiu L., Bo Y., «Efficient distributed clustering using boundary information», Neurocomputing, Vol.275, (2018), pp.2355-2366, https://doi.org/10.1016/j.neucom.2017.11.014.

[7] Ramon-Gonen R., Gelbard R., «Cluster evolution analysis: Identification and detection of similar clusters and migration patterns», Expert Systems with Applications, Vol.83, (2017), pp.363-378, https://doi.org/10.1016/j.eswa.2017.04.007

[8] Yoon S., Nadvi K., «Industrial clusters and industrial ecology: Building 'eco-collective efficiency' in a South Korean cluster», Geoforum, Vol.90, (2018), pp.159-173, https://doi.org/10.1016/j.geoforum.2018.01.013.

[9] Gadea-Rivasa M.Dolores, Gómez-Loscosb A., Bandrésa E., «Clustering regional business cycles», Economics Letters, Vol.162, (2018), pp.171-176, https://doi.org/10.1016/j.econlet.2017.10.029.

[10] Press I., Proof C., «Research on social data by means of cluster analysis», Applied Computing and Informatics, available online: http://2018, last visit:21.02.2018, https://doi.org/10.1016/j.aci.2018.02.003.

[11] Li P., Gu W., Wang L., Xu B., Wu M., Shen W., «Dynamic equivalent modeling of two-staged photovoltaic power station clusters based on dynamic affinity propagation clustering algorithm», International Journal of Electrical Power \& Energy Systems, Vol.95, (2018), pp.463-475, https://doi.org/10.1016/j.ijepes.2017.08.038.

[12] Saxena A., Prasad M., Gupta A., Bharill N., Patel Om P., Tiwari A., Joo E. Meng, Weiping D., Chin-Teng L., «A review of clustering techniques and developments», Neurocomputing, Vol.267, (2017), pp.664-681, https://doi.org/10.1016/j.neucom.2017.06.053

[13] Kouki M., Cardin O., Castagna P., Cornardeau C., «Input data management for energy related discrete event simulation modeling», Journal of Cleaner Production, Vol.141, (2017), pp.194-207, https://doi.org/10.1016/j.jclepro.2016.09.061.

[14] Magdiel A., Ferreira S., Oliveira C., Carlos F., Mattos A., Cavalcantea T., Eduardo J., Marambiob S., «Pattern recognition as a tool to support decision making in the management of the electric sector. Part II: A new method based on clustering of multivariate time series», International Journal of Electrical Power \& Energy Systems Vol.67, (2015), pp.613-626, https://doi.org/10.1016/j.ijepes.2014.12.001.

[15] Grigoras G., Scarlatache F., «An assessment of the renewable energy potential using a clustering based data mining method. Case study in Romania», Energy, Vol.81, (2015), pp.416-429, https://doi.org/10.1016/j.energy.2014.12.054.

[16] Dubovik V. S., "Formation of innovative clusters as a method of activization of innovative activity in the region's economy," The Productive forces of Ukraine, Vol.1, (2009), pp.153-163.

[17] Ermakova A. A., Economic efficiency of cluster functioning: assessment and analysis of the impact on the competitiveness of the region, Actual problems of Economics, Vol.11, (2012), pp.174-180.

[18] Resolution No. 1101 from 09.06.2016, the National Commission, carrying out state regulation in spheres of power and utilities. Access mode: http://www.teplodkp.lutsk.ua/units/menus/uploads/files/1101.pdf.

[19] Annual report of the Poltava oblast utility production enterprise of heat economy " Poltavateploenergo for 2015. - Access mode: https://drive.google.com/file/d/0B8f8g4LSjUbQSENsRU1oZU1YQ Ws/view.

[20] Shishmaryova, A. A., Clusters in the economy of Ukraine [Electronic resource] / O. A. Shishmaryova / the Sixth allUkrainian scientific-practical conference "Actual problems of modern science". Access mode: http://intkonf.org/shishmarova-ooklasteri-v-ekonomitsi-ukrayini. 